\title{
The Influence of Organizational Culture in Application of Information Technology Governance
}

\author{
Lanto Ningrayati Amali ${ }^{11^{*}}$, Lillyan Hadjaratie ${ }^{2)}$, Sitti Suhada ${ }^{3)}$ \\ 1)2)3) Universitas Negeri Gorontalo \\ Jl. Jend Sudirman No.6, Gorontalo, Indonesia \\ 1)ningrayati_amali@ung.ac.id \\ ${ }^{2)}$ lillyan.hadjaratie@ung.ac.id \\ 3)sittisuhada@ung.ac.id
}

Article history:

Received 25 September 2017 Revised 18 December 2017

Accepted 10 January 2018

Available online 28 April 2018

Keywords:
IT development
IT governance
OCAI
Organizational culture

\begin{abstract}
In this era of globalization, an organization needs to adapt to the competitions in order to maintain its existence. However, information technology (IT) governance development and application is sometimes not effective, which consequently ends as a failure. Such extent is attributable to lack of thorough analysis of organizational needs, particularly, in the scope of organizational culture. In this regards, this study attempts to carry out the contributions of organizational culture aspect to the development of IT governance. Good strategies of IT governance are ordinarily well applied in most organizations. The organizations, in fact, struggle to find a proper framework or model of IT governance with their characters. A quantitative method through document study and questionnaire. The data were obtained through The Organizational Culture Assessment Instrument (OCAI) questionnaire with 450 respondents. The importance of organizational culture towards the application of IT governance that an organization can decide a suitable model of development with the organization goals. The role of organizational culture is crucial for the leader, as one key factor of success in IT governance, in formulating harmonious strategies of IT utilization policy with business strategy. Furthermore, it also acts as a recommendation for organizations to design better IT governance which is suitable for organization strategies and vision.
\end{abstract}

\section{INTRODUCTION}

The term "organizational culture" stands for a value system practiced by an organization which governs the members to work and behave based on the values believed. A strong organizational culture is said to be a key component which affects the organization's performance to compete for success [1]. This extent that, it is a contributing factor of better IT governance implementation. In general, IT governance strategies are well executed by most organizations or institutions. On the other hand, selecting the best framework or model of governance that matches the organizations' characteristic is quite a troubles one job. This problem also occurred in Universitas Negeri Gorontalo (UNG). One of the factors is a lack of careful analysis of needs, chiefly in the viewpoint of organizational culture. As a result, it contributes to the ineffectiveness of IT development in the organization. They agree that organizational culture could do a favor in successful IT governance implementation [2][3] In maintaining its existence, internal revamping for an organization is vital to carry out, as a response to aspirations demanding for changes in order to compete on a bigger scale and to reach its business goals. The change as a movement from current point to the desired state in the future [4]. In addition, changes can as well arise because of external factors,

\footnotetext{
${ }^{*}$ Corresponding author
} 
is a benchmark for the board of management to foresee any necessary change for improvement. Moreover, in applying its strategies, an organization can refer to its culture that goes well with its vision and mission [5].

By this consideration, an analysis of organizational culture is recommended to perform, mainly in the application of IT governance. Organizational culture is further treated as a guideline in IT governance maintenance and improvement. Moreover, in choosing a model of IT governance, organizations should involve their signature features as a consideration, since no exact model of the best framework can suit every organization out there. With that in mind, organizational culture is significant as a reference in formulating goals associated IT governance.

\section{LITERATURE REVIEW}

\section{A. Organizational Culture}

Organizational culture as an experience, history, belief, and a sort of shared norms as signature traits of an organization [6]. It is also regarded as main values, as a work philosophy spreading inside an organization to its members, and as a guideline for the organization policy in managing its members and customers [7]. Meanwhile that, organizational culture is a pattern of shared basic assumptions referred by members of an organization as an effective problem-solving tool of external factors adjustments and integration of internal factors [8]. It then guides the members how to perceive, think, and feel their organization problems.

Furthermore, organizational culture does affect the implementation of IT governance [3]. Thus, managing culture is vital to raise the members' awareness on matters related to performance management and as a communication between sides with different standing. Organizational culture should be one of the main focuses for better IT governance application and efficiency [2][9]. Likewise, it is emphasized for an organization to uphold balance between IT/IS and organizational culture as a gate to maximum potency guaranteed by the system [10]. Additionally, organizational culture supports the connection of technology embracement and organization progress [11] and a fundamental issue of well developed and well applied IT governance [12].

Features of a strong organizational culture (integrity, responsibility, accountability, and behavior ethics) can act as a basis for an organization to apply IT governance [13]. Similarly, the central role of organizational culture for a better achievement in projects involving organizational change, including IT [10]. Organizational culture can raise the members' awareness and sense of collectivism, guide how to solve problems, and govern how the members behave. Should there be a contradiction between IT and organizational culture, one must choose to reject the governance or to adjust it to the existing organizational culture.

\section{B. IT Governance}

A number of different arguments on IT governance show that there is clear perspective towards the idea of IT governance itself. All put focus on the similar issue, i.e., role of IT governance in a synergizing relation of IT with organization's business and risk minimization. IT governance has been one key part of an organization's management because fine governance can ensure that IT can uphold and expand organization's strategies and goals. IT governance is aimed to guarantee that IT implementation can accomplish the mission set in organization's strategy, for instance, maximum utilization of IT, capturing benefits from opportunities, responsible handling of IT sources, and risk control and minimization [14][15]. Thus, investing in IT governance helps quite much in the long run [16].

There is at least 40 percent profit on IT investment experienced by organizations with well managed IT governance policies. Moreover, the organizations were able to collect 40 percent more investment refund than their competitors. It also affected their performance, boosting it to 20 to 40 percent [17][18][19]. A well established IT governance plays a key role for organizations to increase performance and success rate, enabling them to meet their strategic targets. Thus, one requires having a broad conception on IT governance to set limitation and scope of function of IT governance. This eases the organizations to have a broader outlook towards their business prospects and provides a focus for the management to notice. A proper implementation of IT governance is substantial to stimulate specific benefits of business, e.g, increasing reputation, trust, and cost suppression [20]. Furthermore, it is aimed to create better synergy with the surrounding community, business circumstances, and interested parties. Henceforth, an organization needs to understand completely of contributing factors of IT governance in regards to being superior to the competitors and making the most of the value delivery of IT projects related to IT investments [21].

Consequently, effective IT governance can ensure that IT sustains organization goals and optimizes business investment and IT risk management. At present, there is no way that an organization without IT and information system (IT/IS) can provide a reference for the executive management in decision making. As a matter of responsibility of leadership and management board, IT governance can assure the needs and aims of the 
organization. There is an increase of interest by organizations regarding IT governance since it is claimed that there is a gap between large facilities of IT projects and lack of control of organization's performance. Therefore, an efficient management of IT/IS is significant to perform better in matters of operational management and organization tactic.

\section{METHODS}

\section{Flexibility and Discretion}

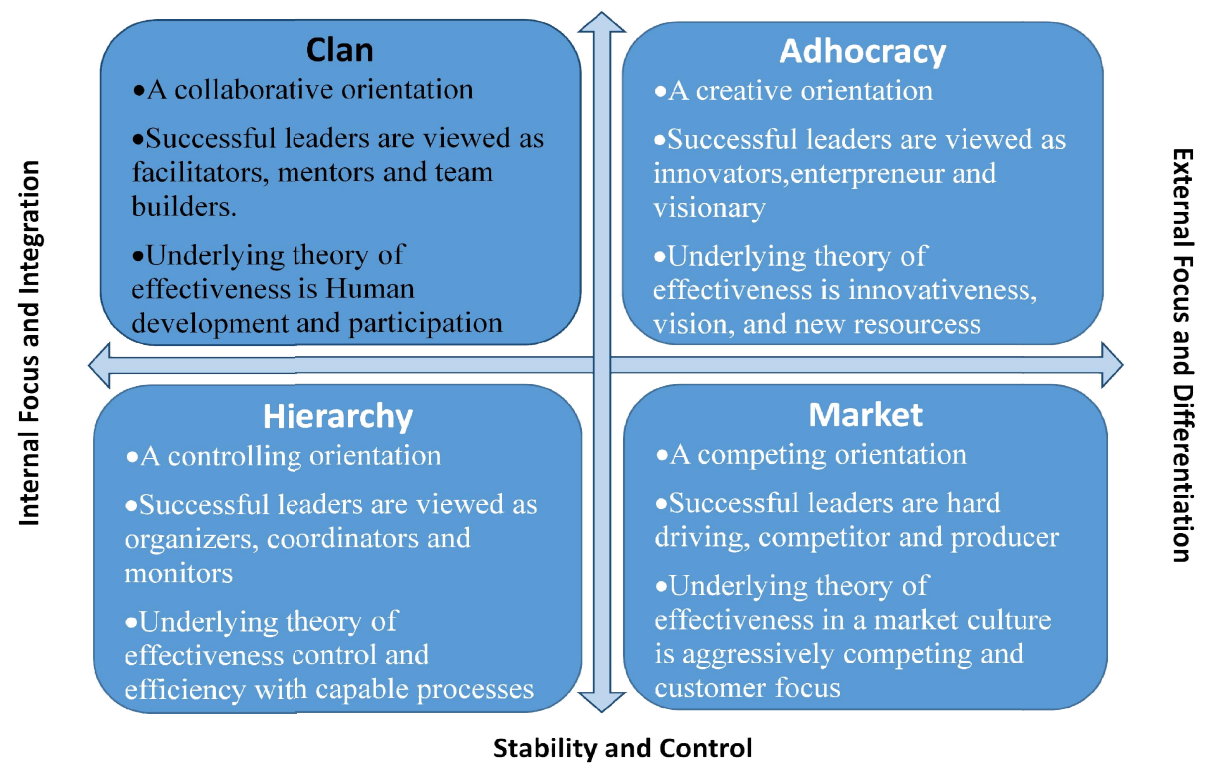

Figure 1. The competing value framework

Taking place in UNG, the study was carried out through a quantitative method, referring to its focus and expected output. This research utilized The Organizational Culture Assessment Instrument (OCAI) questionnaire for data collection, which is proposed by [22], as displayed in Figure 1. OCAI is a psychometric tool for purposed to help and preferred culture. Organizations both the current cultural state and also to identify gaps between current and desired futures [23].

OCAI model comprises four types of organizational culture. It involves six variables of the cultural dimension, i.e., Dominant Characteristic, Organizational Leadership, Management of Employees, Organizational Glue, Strategic Emphases, and Criteria of Success [22]. On every variable, there are four questions; each represents four types (A, B, C, D) of organizational culture. A type stands for Clan Culture; B is for Adhocracy Culture; C and D refer to Market Culture and Hierarchy Culture respectively. In addition, this research conducts document study in order to provide a more in-depth analysis of the issue being addressed.

The population included 925 respondens at UNG. It set its sample by Simple Random Sampling technique which estimates 254-278 target samples with 95 percent confidence level and five percent margin of error, as adopted from [24]. That moderate level of certainty must be on 95 percent, considering that target samples need to represent the population of research [24].

\section{RESULTS}

After data collections are complete from 450 respondents only 268 returned the questionnaires, the data can be entered, edited and viewed into SPSS 16.0 in the data file. In regard to data screening and cleaning, the purpose of data screening is to ensure the data is clean of ambiguous data and errors. Ambiguous data can have an effect or negative influence on the outcomes. The data from the questionnaires were cleaned and resulted in 241 analyzable data.

This research obtained an average recapitulation of respondents' answer of each variable in six dimensions of organizational culture and the overall profile of organizational culture, which is the average score of all six 
dimensions. It is presented in Table 1. Moreover, based on Table 1 shown in Figure 2 and 3 display graphs of current culture dimension in the respondents work environment and preferred culture dimension respectively.

TABLE 1

AVERAGE ASSESSMENT OF SURVEY RESULTS

\begin{tabular}{lcccccccc}
\hline \hline \multicolumn{1}{c}{ Dimensions of Organizational } & \multicolumn{4}{c}{ Culture } & Current & \multicolumn{3}{c}{ Preffered } \\
\cline { 2 - 9 } Dominant Characteristic & A & B & C & D & A & B & C & D \\
\cline { 2 - 8 } Organizational Leadership & 25 & 23 & 26 & 25 & 27 & 25 & 24 & 24 \\
Management of Employees & 25 & 25 & 27 & 27 & 25 & 24 & 25 \\
Organizational Glue & 25 & 23 & 26 & 26 & 28 & 25 & 24 & 24 \\
Strategic Emphases & 24 & 25 & 26 & 27 & 26 & 23 & 24 \\
Criteria of Success & 25 & 24 & 26 & 26 & 28 & 26 & 24 & 23 \\
The Overall OC Profiles & 25 & 23 & 26 & 26 & 28 & 25 & 24 & 23 \\
\hline
\end{tabular}

Note: $A=$ Clan $;=$ Adhocracy; $C=$ Market $D=$ Hierarchy

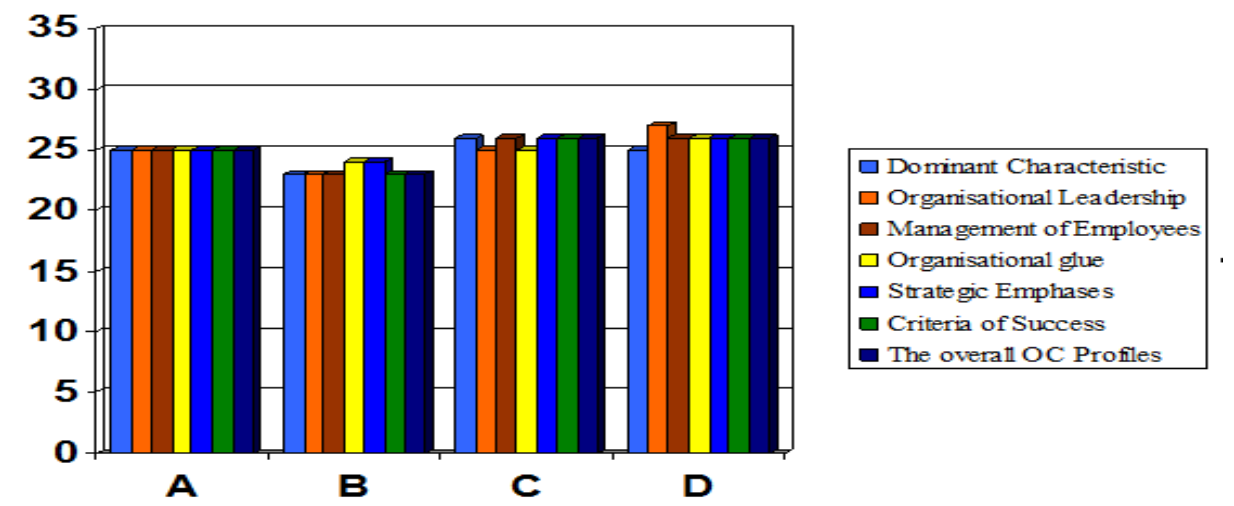

Figure 2. Graph of the current cultural

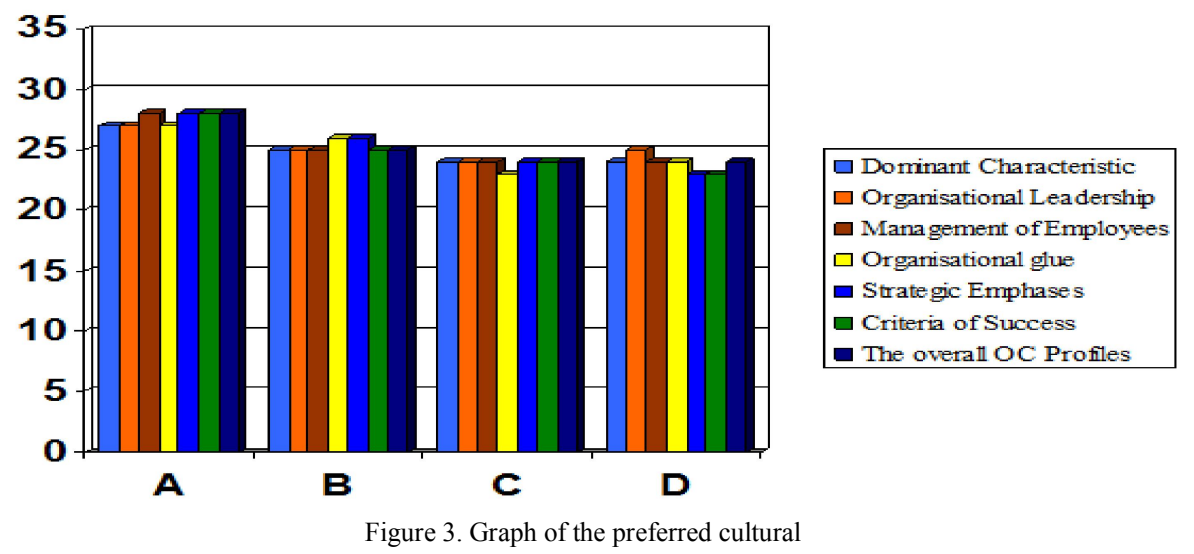

The result in Table 1 displays the average score of organizational culture profiles based on the six culture dimensions. Figures 4 to 9 show a percentage breakdown of the current culture profiles and preferred ones. This research formulates a conceptual of IT governance based on six culture dimensions. The conceptual is recommended as a guideline for the leader to plan strategic vision, implement projects and design new regulations.

\section{DISCUSSION}

\section{A. Dominant Characteristic}

Figure 4 displays the average score tabulation of a dominant characteristic of the organizational culture profiles. Of the current culture profiles, market type appears to be the most dominant profile of 26 percent, while adhocracy 
being the least dominant with 23 percent. The second and third place in the hierarchy and clan culture, both scoring 25 percent. The market type culture lays emphasis on a goal oriented and competitive work environment.

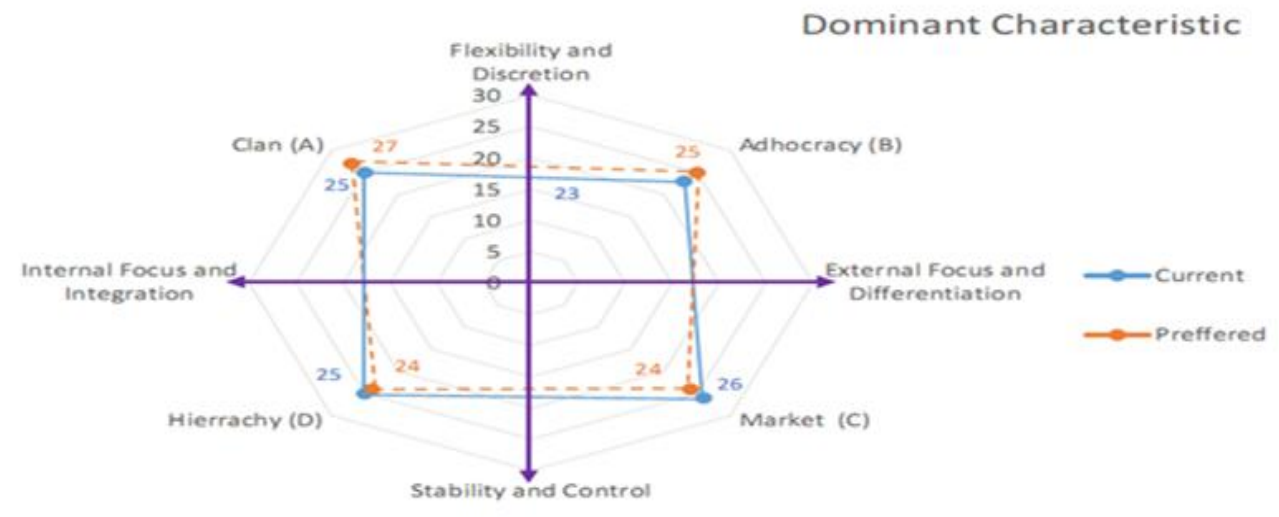

Figure 4. Radar diagram of dimension of dominant characteristic

The result implies that organization aims for competitive excellence and successful target achievement. An organization can not solely rely on strong human and financial resources in order to become superior to its competitors. It is crucial for the organization to possess adaptive, objective, and transparent management system. This idea is also supported that superiority does not measure an organization's capability to maintain its existence, but its adaptability towards change [25]. This is to say that it is crucial to have a leader with decent competence in business skills and strategies to support IT/IS strategies of the organization.

Furthermore, the clan culture appears to be the most dominant preferred culture profile, being at 27 percent, followed by adhocracy culture at 25 percent. Meanwhile, the respondents preferred to decrease the likelihood of market and hierarchy culture for two percent and one percent respectively. In contrast, as shown from the result the respondents preferred to increase clan and adhocracy culture for three percent and one percent respectively. From this set of data, it is concluded that aspiration for change inside the organization is less significant. Once a change is considered necessary, a leader should put more attention to organizational needs and encourage or boost the members' performance. It is also essential for the leader to develop management competence to facilitate internal revamping.

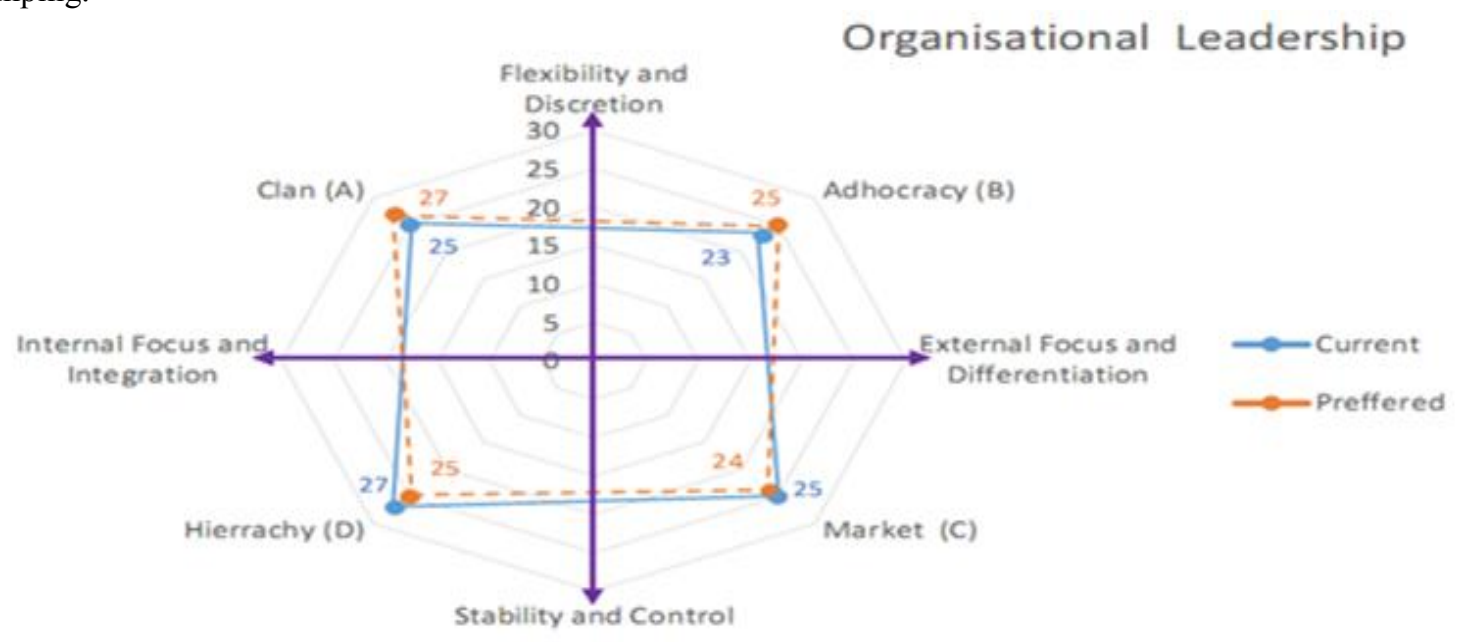

Figure 5. Radar diagram of dimension of organizational leadership

\section{B. Organizational Leadership}

Figure 5 elaborates features of organizational culture profiles based on the organizational leadership dimension. As the most dominant profile of current culture, hierarchy culture highlights on coordination based leadership style. In the second place, market culture emphasizes on a competitive style leadership which demands the leader to be able to boost the members' motivation. Both of these leadership styles have a vital contribution to IT/IS development if applied properly. 
As the most dominant in preferred culture profiles, clan culture stresses on mentor style leadership. The leader in this culture profile plays a role as a mentor and facilitator. Moreover, it implies that the organization also demand an entrepreneurship style leadership as well as a leader with maximum job efficiency. With the desire for hierarchy culture to decrease, it seems that the organization prefers a flexible leadership style, which is also under the organizational limit at the same time. In this situation, staff can freely provide feedback to the organization.

From the analysis of this dimension, it can be concluded that all employees seek to shift to a culture that resembles clan type profile, with mentorship style leadership. The respondents expected that a leader could motivate IT/IS staff with different backgrounds to synchronize in improving IT governance.

\section{Management of Employees}

Figure 6 presents data of organizational culture profiles based on the dimension of management of employees. In the current dominant culture profile (hierarchy culture), the management focuses on providing the sense of safety and routine based stable interconnection between members. It also appears that a number of current personal management styles resemble the market culture, which encourages the person to be more competitive in IT/IS service. On the contrary, in the preferred culture profile, there is a desire to increase the clan culture for three percent and to decrease the hierarchy and market culture for two percent. It can be achieved by putting more emphasis on teamwork, the solidarity of members, and internal management. The organization may need human resource training program in IT/IS sector with measurable targets as a way to support the personnel management. The organization also needs to develop a flexible communication between the staff and the management to enhance members' creativity and performance.

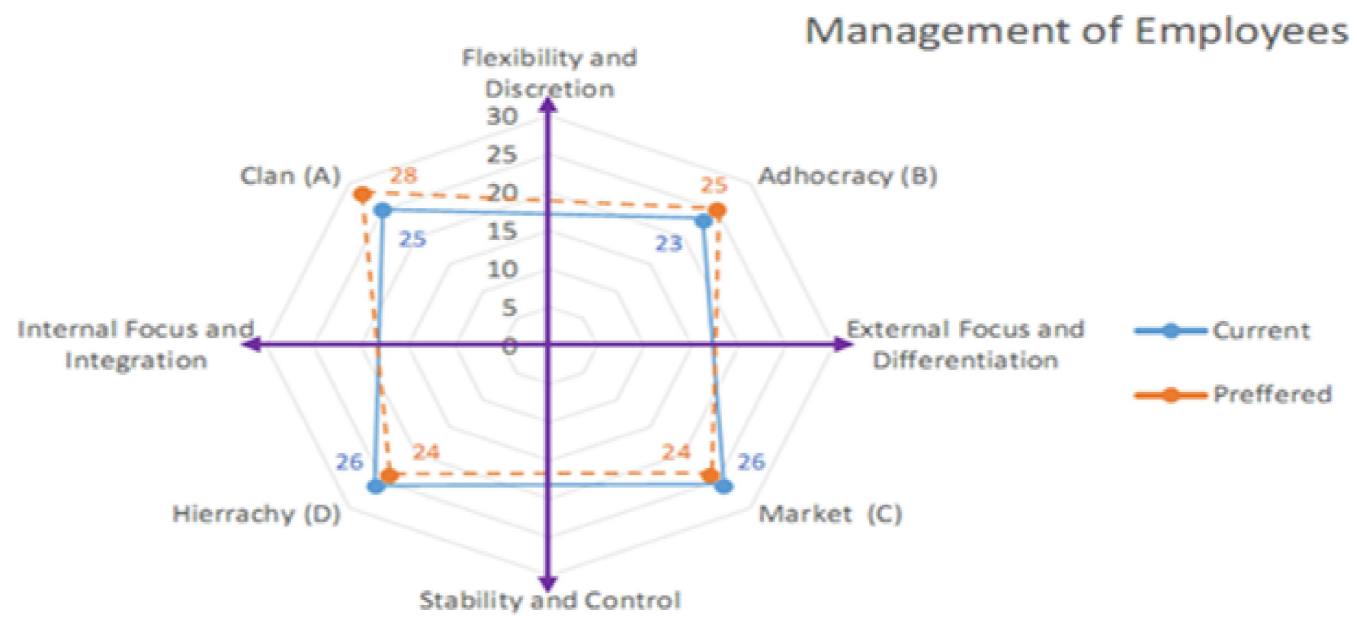

\section{Organizational Glue}

Figure 7 shows an elaboration of organizational culture profiles based on the dimension of organizational glue. As mentioned previously, hierarchy culture is the most dominant profile in this organization, followed by clan and market culture as the second most dominant and adhocracy culture as the least dominant profile, In a hierarchy type dominant organization, the main glues among members are formal regulations and policy.

Moreover, the members of this organization appear to be united by the principles of loyalty, shared belief, commitment, achievement, target accomplishment, and aggressiveness. These principles resemble the clan and market culture as the second most dominant profiles. On the other hand, adhocracy culture is the least contributing factor to bond the members that lead them to focus on innovation and organization development. Also, there seems to be a desire from the staff to reduce the likelihood of hierarchy culture for two percent. It can be seen from the organization needs to cut a bit of the strictness of formal regulation and policy as its organizational glue. The change needs to be implemented in order to create flexible cooperation among members, which in turn improves staffs' performance. Additionally, the respondents demand an increase of two percent in the clan culture profile. This is to say that the members of the organization are more likely to be united by loyalty and shared beliefs rather than formal regulation and policy. 


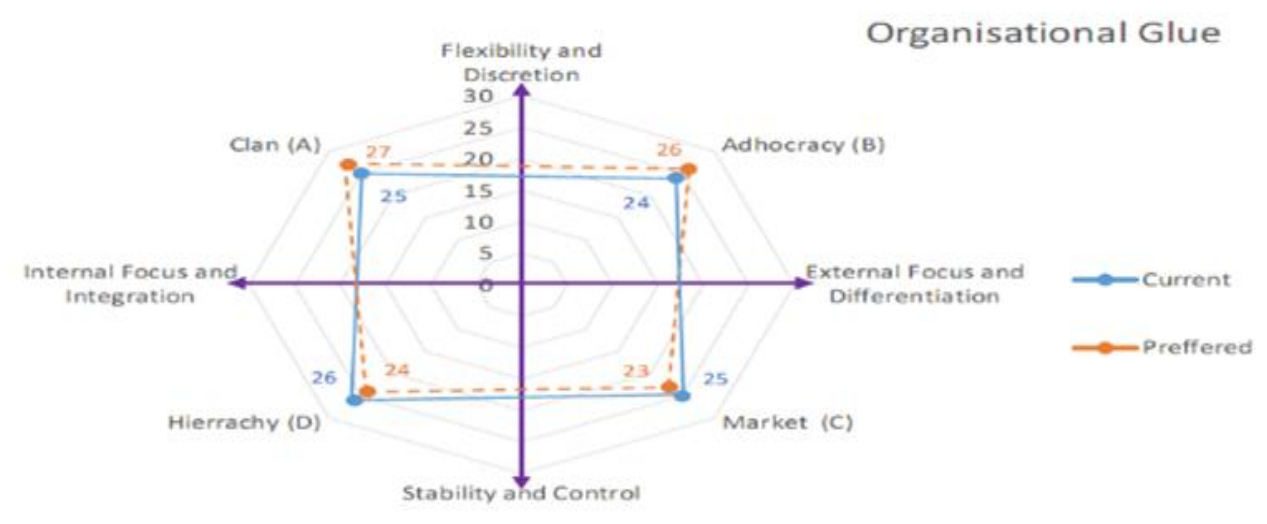

Figure 7. Radar diagram of dimension of organizational glue

\section{E. Strategic Emphases}

Figure 8 outlines the analysis result of profiles of organizational culture by strategic emphasis variable. As the most dominant profile of current culture, hierarchy culture underlines its strategies to address internal problems, e.g. internal revamping and stabilization of IT/governance to accomplish target. In addition, some respondents argue that the strategic emphasis of the organization resemble those of market and clan culture, i.e., competitive target achievement and expansion of service coverage.

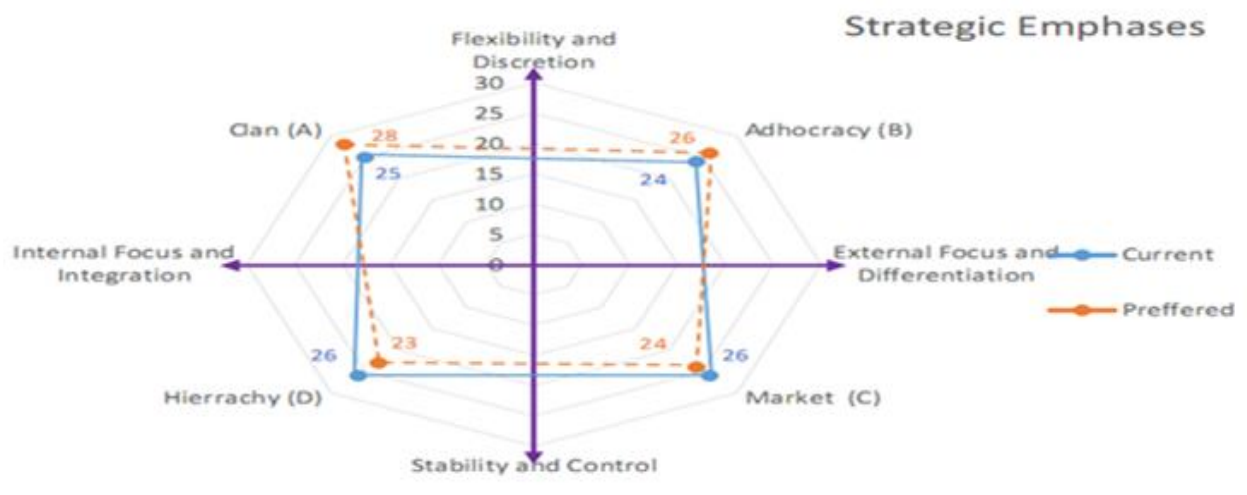

Figure 8. Radar diagram of dimension of strategic emphasis

\section{F. Criteria of Success}

Figure 9 portrays data breakdown of organizational culture profiles viewed from the dimension of criteria for success. The hierarchy culture seems to dominate the current culture profile followed by the market and clan culture at the second place, and adhocracy culture being the least dominant. By the percentage, it is inferred that the organization determines its criteria of success based on efficiency in IT governance, reliable IT/IS service products, and expansion of service coverage area of IT/IS. In addition, the adhocracy culture contributes the least to the organization's mindset of success criteria. It sets a benchmark of success on the innovation of IT/IS services. 


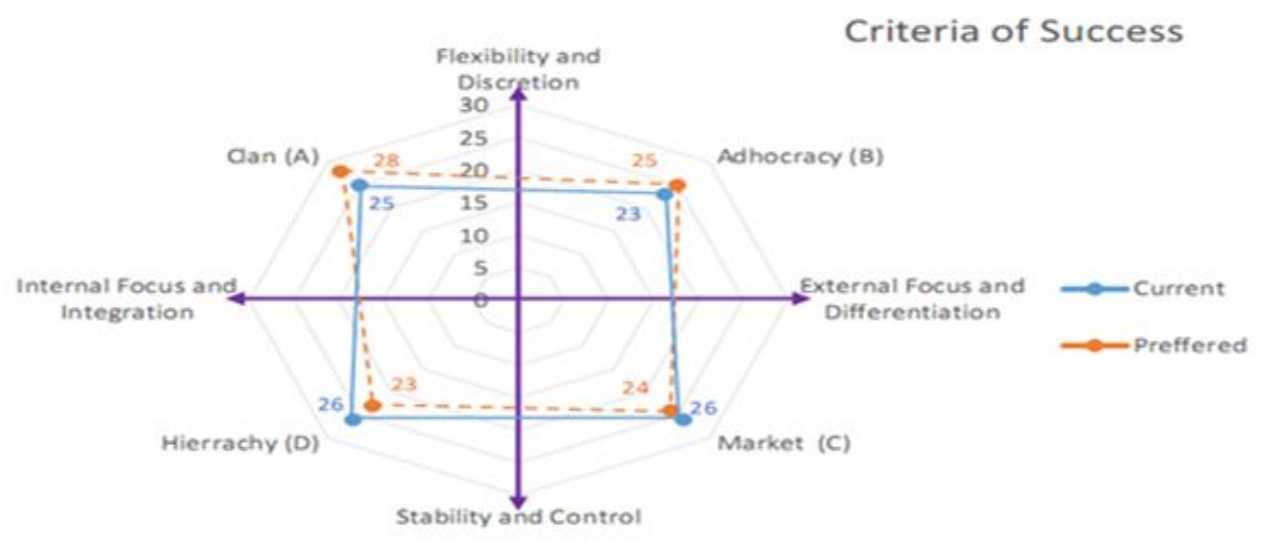

Figure 9. Radar diagram of dimension of criteria of success

Furthermore, the outline of preferred culture profiles implies that the organization favors setting a benchmark of success in human resource development, improvement in internal management, and teamwork and solidarity among the members. In this case, an internal evaluation becomes vital as an effort of improving the quality of human resource, and IT/IS services.

Furthermore, the result of respondents' points on preferred culture displays a quite small surge for an increase in four cultures. There is a desire to increase three percent of the likelihood of clan culture, while adhocracy culture is preferred to increase two percent. Conversely, the respondents would rather both market and hierarchy culture to drop two percent. Furthermore, as extracted from the data, the desire to increase or decrease the level of existing organizational culture is below five percent. This means that the respondents' need for change inside the organization is less significant.

The preference of respondents to move to clan type organizational culture is attributable to the features of clan cultures. Clan culture puts emphasis on human resource development, flexibility and dynamics of an organization, and solidarity between its members. Moreover, in the next position, adhocracy culture tends to focus on growing motivation to innovate, encouraging risk-taking actions, and embracing changes and challenges ahead. Furthermore, as elucidated from the statistics, a desire for change is not needed in the near future as the gap between current culture and preference is less than two percent.

\section{G. Organizational Culture Profile}

This research performed an analysis on the average recap data from the questionnaires. The result provides a radar diagram of organizational culture percentage from numeric data from respondents' score on each six dimension of four organizational culture profiles (see Table 1). It is then presented in Table 2.

TABLE 2.

THE OVERALL OC PROFILES RELATED TO THE SIX KEY DIMENSIONS Overall Percentage (\%)

\begin{tabular}{lllll}
\multicolumn{5}{c}{ Overall Percentage (\%) } \\
\hline Organizational Culture & A & B & C & D \\
Current & 25 & 23 & 26 & 26 \\
Preffered & 28 & 25 & 24 & 24 \\
\hline
\end{tabular}

Note: $A=$ Clan $; B=$ Adhocracy; $C=$ Market D $=$ Hierarchy

The result (in Figure 10) shows that there are currently two dominant organizational culture profiles, hierarchy and market culture, both share a similar portion of 26 percent. These cultures emphasize on strict control of stabilized, well structured and goal oriented work environment, well organized formal procedures, and a strong focus on competition and target achievement. Contrarily, at the level of 23 percent, adhocracy culture is the least dominant culture, followed by clan culture in the third place, being at 25 percent. A less than five percent gap between the first and the last position designates the weakness of organizational culture inside an organization. From the result, it is deduced that organization is believed to have fewer benefits regarding performance. This is crucial for a deep valued organizational culture that is fundamental in well managed IT governance and lucrative projects (including IT ones). This state, nevertheless, is still bearable to some extent that the organization is in its process of finding suitable organizational culture. 


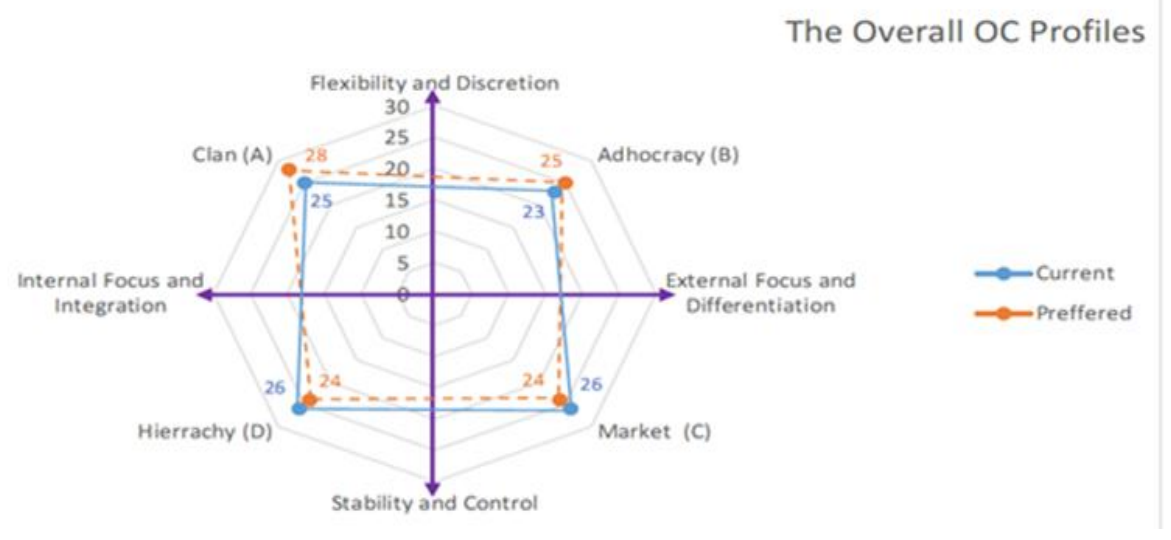

Figure 10. Radar diagram of dimension of overall organizational culture profiles

Furthermore, the result of respondents' points on preferred culture displays a quite small surge for an increase in four cultures. There is a desire to increase three percent of the likelihood of clan culture, while adhocracy culture is preferred to increase two percent. Conversely, the respondents would rather both market and hierarchy culture to drop two percent. Furthermore, as extracted from the data, the desire to increase or decrease the level of existing organizational culture is below five percent. This means that the respondents' need for change inside the organization is less significant.

The preference of respondents to move to clan type organizational culture is attributable to the features of clan cultures. Clan culture puts emphasis on human resource development, flexibility and dynamics of an organization, and solidarity between its members. Moreover, in the next position, adhocracy culture tends to focus on growing motivation to innovate, encouraging risk-taking actions, and embracing changes and challenges ahead. Furthermore, as elucidated from the statistics, a desire for change is not needed in the near future as the gap between current culture and preference is less than two percent.

\section{CONCLUSIONS}

To sum up, market and hierarchy type culture still dominate the current and preferred organizational culture of the respondents. Both market and hierarchy cultures are on similar percentage, scoring 26 percent of current culture and 24 percent preferred culture with two percent gap. On the other hand, adhocracy culture is on bottom position, followed by clan culture in the third place. In clan culture, the current culture is at 25 percent, and the preferred is at 28 percent with a gap of 3 percent. Meanwhile, there is 23 percent current value of adhocracy culture, with 25 percent preferred culture value and two percent gap. Since the gap between cultures is less than five percent, it is therefore deduced that significant change of organizational culture is not needed. Based on the result above on organizational culture profiles, it is crucial for the leader, as one key factor of success in IT governance, to possess proper accountability in formulating harmonious strategies of IT utilization policy with business strategy. Moreover, in IT governance, one needs to consider establishing risk management actions and staff training to anticipate any failure in IT projects. Furthermore, every policy released by the administration needs to maintain its value of transparency, as well as being open for aspirations from members, to further encourage organization's advancement from bottom level work units.

\section{ACKNOWLEDGMENTS}

The research for this paper was financially supported by Ministry of Research, Technology and Higher Education, Indonesia.We would like to thank LPPM, Universitas Negeri Gorontalo.

\section{REFERENCES}

[1] Chutimon Satidularn, Kerry Tanner, and Carla L Wilkin, "Exploring IT Governance Arrangements in Practice : The Case of a Utility Organization Thailand," in Pacific Asia Conference on Information Systems, PACIS, Thailand, 2011, p. 163.

[2] R Pereira and M M Silvia, "A Literature Review : Guidelines and Contingency Factors for IT Governance," in European, Mediterranean \& Middle Eastern Conference on Information Systems, Munich, Germany, 2012, pp. 342-360.

[3] Lazar Rusu, Parisa Aasi, and Shengnan Han, "The Influence of Organizational Culture on IT Governance Performance : Case of the IT Departement in a Large Swedish Company," in 49th Hawaii International Conference on System Sciences, Hawaii, 2016, pp. 5156-5165. 
[4] R Potts and Marsh J La, Managing Change for Success. London: Ducan Baird, 2004.

[5] R Kasali, Public Relations Management Concepts and Application in Indonesia. Jakarta: Pustaka Utama Grafiti, 2008.

[6] R E Griffin and R J Ebert, Bussiness \& Economics. New Jersey: Prentice Hall, 2008.

[7] S P Robbins and T A Judge, Organizational Behavior. New Jersey: Pearson Education, 2013.

[8] E H Schein, Organizational Culture and Leadership. San Fransisco: Jossey Bass, 2008.

[9] ISACA, COBIT 5 Executive Summary. Rolling Meadows USA : IT Governance Institute. USA: IT Governance Institute, 2012.

[10] W Ke and K K Wei, Organizational Culture and Leadership in ERP Implementation Decision Support System. USA, 2008.

[11] J A Chatman and K A Jehn, "Assessing the Relationship Between Industry Characteristics and Organizational Culture : How Different You Be?," Academy of Management Journal, vol. 37, no. 3, pp. 522-553, June 1994.

[12] W G Indeje and Q Zheng, "Organizational Culture and Information Systems Implementation : A Structuration Theory Perspective Sprouts," Working Papers on Information System, vol. 10, no. 27, pp. 1-14, 2010.

[13] H Nugroho, "Organizational Culture Analysis as Contingency Factor in Application of IT Governance in Politeknik Telkom," in Seminar Nasional Sistem Informasi Indonesia, Desember 2013, pp. 58-63.

[14] ITGI, Global Status Report on the Governance of Enterprise IT (GEIT). USA: IT Governance Institute, 2011.

[15] M Y Lin, N H Arshad, H Haron, M Yusoff, and A Mohamed, "IT Governance Awareness and Practice : An Insight from Malaysian Senior Management Perspective.," Journal of Business Systems, Governance and Ethics, vol. 5, no. 1, pp. 43-57, January 2010.

[16] N K Kakabadse and A Kakabadse, "IS/IT Governance : Need for an Integrated Modal," Journal Copporate Governance, vol. 1, no. 4, pp. 9$11,2001$.

[17] P Weil and J W Ross, IT Governance, How Top Performers, Manage IT Decision Rights for Superior Results.: Harvard Bussiness School Press, 2004.

[18] Mueller Carsten, "Linkage Mechanism for Component based Services and IT Governance," Journal of Systems Integration, vol. 4, no. 1, pp. $1-10,2013$.

[19] Huo Lingyu, Liu Bingwu, Yuan Ruiping, and Wu Jianzhang, "IT Governance Framework of ERP System Implementation," in International Conference on Computing, Control and Industrial Engineering (CCIE), 2010, pp. 431-434.

[20] C H Lee, J H Lee, J S Park, and K Y Jeong, "A Study of the Causal Relationship between IT Governance Inhibitors and Its Success in Korea Enterprises," in Proceedings of the 41st Hawaii International Conference on System Sciences, vol. 4, Korea, 2008 , pp. 1-11.

[21] L N Amali, M Mahmuddin, and M Ahmad, "Towards Good Monitoring IT Governance in Public Sector Organizations," ARPN Journal of Engineering and Applied Sciences, vol. 10, no. 3, pp. 1203-1209, 2015.

[22] K Cameron and R E Quinn, Diagnosing and Changing Organizational Culture. San Fransisco: Jossey Bass, 2011.

[23] J Suderman, "Using the Organizational Cultural Assessment (OCAI) as a Tool For New Team Development," Journal of Practical Consulting, vol. 4, no. 1, pp. 52-58, 2012.

[24] M Saunders, P Lewis, and A Thornhill, Research Methods for Business Students (5th Ed). England: Prentice Hall, 2009.

[25] Rondonowu, "Improving Competitive Advantage of University Through Porter Industry Structure Analysis," Mediator, vol. 4, no. 1, pp. 105-111, 2003. 